\title{
INCREASING THE MECHANICAL PROPERTIES OF STRUCTURAL CAST IRON FOR MACHINE-BUILDING PARTS BY COMBINED Mn-AI ALLOYING
}

\author{
Stanislav Popov \\ PhD, Associate Professor \\ Department of Industrial Engineering \\ Poltava State Agrarian University \\ 1/3 Skovorody str., Poltava, Ukraine, 36003 \\ Liliia Frolova $₫$ \\ Research Department \\ PC TECHNOLOGY CENTER \\ 4 Shatilova Dacha str., Kharkiv, Ukraine, 61165 \\ Department of Foundry ${ }^{1}$ \\ Liliia.Frolova@mit.khpi.edu.ua \\ Oleksii Rebrov \\ Department of Car and Tractor Industry ${ }^{l}$ \\ Yevheniia Naumenko \\ Department of Integrated Management Technologies ${ }^{2}$ \\ Olena Postupna \\ Department of Management at Training Research and Production Center \\ National University of Civil Defence of Ukraine \\ 94 Chernyshevska str., Kharkiv, Ukraine, 61023 \\ Vladyslav Zubko \\ Department of Tractors, Agricultural Machines And Transport Technologies \\ Sumy National Agrarian University \\ 160 H. Kondratiieva str., Sumy, Ukraine, 40021 \\ Pavel Shvets \\ Department of Power Supply and Energy Management ${ }^{2}$ \\ INational Technical University «Kharkiv Polytechnic Institute» \\ 2 Kyrpychova str., Kharkiv, Ukraine, 61002 \\ ${ }^{2}$ National University «Odessa Polytechnic» \\ 1 Shevchenko ave., Odessa, Ukraine, 65044
}

$\triangle$ Corresponding author

\section{Abstract}

The object of research in this work was cast iron for machine-building parts, alloyed with Al. The possibility of improving the mechanical properties of cast iron by choosing the optimal $\mathrm{Mn}-\mathrm{Al}$ combinations, depending on the carbon content in the cast iron, was determined. The study was carried out on the basis of available retrospective data of serial industrial melts by constructing the regression equation for the ultimate strength of cast iron in the three-factor space of the input variables $\mathrm{C}-\mathrm{Mn}-\mathrm{Al}$. The optimization problem was solved by the ridge analysis method after reducing the dimension of the factor space by fixing the carbon content at three levels: $\mathrm{C}=3 \%, \mathrm{C}=3.3 \%$, and $\mathrm{C}=3.6 \%$.

It was found that the maximum values of the ultimate strength are achieved at the minimum level of carbon content $(\mathrm{C}=3 \%)$ and are in the range of values close to $300 \mathrm{MPa}$. In this case, the $\mathrm{Al}$ content is in the range $(2.4-2.6) \%$, and the Mn content is about $0.82 \%$. With an increase in the carbon content, there is a tendency to a decrease in the content of Mn and $\mathrm{Al}$ in the alloy, which 
is necessary to ensure the ultimate strength close to $300 \mathrm{MPa}$. The results of the ridge analysis of the response surface also showed that at the upper limit of the carbon content $(\mathrm{C}=3.6 \%)$, it is not possible to reach the ultimate strength of $300 \mathrm{MPa}$ in the existing range of $\mathrm{Mn}$ and $\mathrm{Al}$ variation.

All solutions are verified for the following ranges of input variables $\mathrm{C}=(2.94-3.66) \%, \mathrm{Mn}=(0.5-1.1) \%, \mathrm{Al}=(1.7-2.9) \%$.

Graphical-analytical descriptions of the optimal $\mathrm{Mn}-\mathrm{Al}$ ratios are obtained, depending on the actual content of carbon in the alloy, which make it possible to purposefully select the optimal melting modes by controlling the tensile strength of the alloy.

Keywords: alloy, mechanical properties, cast iron, regression equation, ridge analysis, response surface.

DOI: $10.21303 / 2461-4262.2022 .002243$

\section{Introduction}

Fierce competition in the market of metal products, in particular, products of metallurgical production and mechanical engineering, is the factor that stimulates the development of technological innovations in industrial production $[1,2]$. Such innovations are optimal technological solutions in terms of melting [3-6] and out-of-furnace processing of melts [7-10]. The alloys obtained in this case are used for cast machine parts, therefore, the operational reliability of the corresponding units and mechanisms directly depends on the quality of the alloy. The solutions proposed in such studies are based on the creation of conditions under which a targeted formation of a microstructure occurs, which determines the mechanical properties of alloys [11-13]. In this case, the creation of such conditions is based on theoretical and experimental data on the relationship between the chemical composition and properties, taking into account the specifics of the production in which such alloys are produced [14-16]. These data are obtained from mathematical models, which, as a rule, have the form of regression equations, built on the basis of either active [17, 18] or passive planning of the experiment $[19,20]$. On the basis of such equations, the optimal values of the input variables of the investigated object or process are sought. In the presence of restrictions, such a problem is solved either by the methods of ridge analysis [21, 22], or by studying the response surface by its canonical transformation [23, 24]. The latter methods can be considered as research tools within the framework of the general response surface methodology, which is widely used in the study of metallurgical processes [25]. The results obtained in this case are used in control systems for technological processes not only in conditions when one optimization criterion is selected, but also in the presence of several criteria, including competitive ones [26].

Within the framework of the described approaches, a study was carried out earlier [27], in which the problem of the synthesis of aluminum cast iron was solved based on the choice of the optimal Al-Si combination in the alloy and the assessment of the possibilities of obtaining such cast iron in industrial melts. The actual development of this work is the study of the strength of cast iron in the system of elements $\mathrm{C}-\mathrm{Mn}-\mathrm{Al}$. This is due to the fact that $\mathrm{Mn}$ is a carbide-forming element that increases strength, but stimulates a metastable process during crystallization. Therefore, a compensator for the development of a metastable process can be the use of either Si or an increase in the content of $\mathrm{C}$ in the melt. For reasons of economy of ferrosilicon, it is the second way that seems rational. However, in this case, it is necessary to determine how the carbon content affects the position of the $\mathrm{Mn}-\mathrm{Al}$ optima, which will make it possible to calculate the optimal amount of additives in the melt to obtain cast iron with maximum strength. This study is devoted to this.

\section{Materials and Methods}

The research was carried out within the framework of the PC Technology Center research topic «Technological audit and identification of production reserves». Retrospective data of a series of industrial meltings were selected as the initial data [28].

The object of research was cast iron for machine-building parts, alloyed with Al.

The aim of research was to determine the optimal Mn-Al combination that would allow reaching the maximum values of the ultimate strength of cast iron containing different amounts of carbon.

To achieve this aim, the task was to construct an adequate regression equation in a three-factor space of input variables, describing the effect of carbon, manganese and aluminum in the composition of the alloy on its ultimate strength. 
The main hypothesis of the study was that, having solved the optimization problem using the ridge analysis, it is possible to purposefully select the ratio of $\mathrm{Mn}$ and $\mathrm{Al}$, depending on the actual content of carbon in the melt, by controlling the strength of the alloy.

The following were chosen as input variables: $x_{1}$ - content of $\mathrm{C}$ in the alloy, $\%, x_{2}-$ content of $\mathrm{Mn}$ in the alloy, $\%, x_{3}$ - content of $\mathrm{Al}$ in the alloy, $\%$.

Ultimate tensile strength $\sigma_{b}, \mathrm{MPa}(\mathrm{y})$ was chosen as the output variable.

The standardization of these serial industrial meltings was carried out according to the formula [29]:

$$
x_{i}=\frac{2 x_{i}^{*}-\left(x_{i \max }^{*}+x_{i \min }^{*}\right)}{x_{i \max }^{*}-x_{i \min }^{*}}, i=1, . ., N, j=1, ., n, x_{i \max }^{*}=\max _{j} x_{j i}^{*}, x_{i \min }^{*}=\min _{j} x_{j i}^{*},
$$

where the ${ }^{*}$ symbol denotes the natural value of the input variables.

The ranges of variation of the input variables and their normalized values calculated according to (1), as well as the values of the output variable, are given in Table $\mathbf{1 .}$

Table 1

Experiment planning scheme for 3 components $(\mathrm{C}, \mathrm{Mn}, \mathrm{Al})$

\begin{tabular}{|c|c|c|c|c|c|c|c|}
\hline \multirow{3}{*}{$\begin{array}{c}\text { No. of } \\
\text { experiment }\end{array}$} & \multicolumn{6}{|c|}{ Dosage of the investigated components } & \multirow{3}{*}{$\begin{array}{c}\sigma_{b}, \mathrm{MPa} \\
y\end{array}$} \\
\hline & \multicolumn{3}{|c|}{ Conventional units } & \multicolumn{3}{|c|}{ Weight parts } & \\
\hline & $X_{1}$ & $X_{2}$ & $X_{3}$ & $\mathbf{C}$ & Mn & Al & \\
\hline 1 & -1 & -1 & -1 & 3.0 & 0.6 & 1.8 & 221 \\
\hline 2 & +1 & -1 & -1 & 3.6 & 0.6 & 1.8 & 243 \\
\hline 3 & -1 & +1 & -1 & 3.0 & 1.0 & 1.8 & 224 \\
\hline 4 & +1 & +1 & -1 & 3.6 & 1.0 & 1.8 & 240 \\
\hline 5 & -1 & -1 & +1 & 3.0 & 0.6 & 2.8 & 239 \\
\hline 6 & +1 & -1 & +1 & 3.6 & 0.6 & 2.8 & 240 \\
\hline 7 & -1 & +1 & +1 & 3.0 & 1.0 & 2.8 & 286 \\
\hline 8 & +1 & +1 & +1 & 3.6 & 1.0 & 2.8 & 251 \\
\hline 9 & -1.21 & 0 & 0 & 2.94 & 0.8 & 2.3 & 287 \\
\hline 10 & +1.21 & 0 & 0 & 3.66 & 0.8 & 2.3 & 266 \\
\hline 11 & 0 & -1.21 & 0 & 3.3 & 0.5 & 2.3 & 279 \\
\hline 12 & 0 & +1.21 & 0 & 3.3 & 1.1 & 2.3 & 260 \\
\hline 13 & 0 & 0 & -1.21 & 3.3 & 0.8 & 1.7 & 240 \\
\hline 14 & 0 & 0 & +1.21 & 3.3 & 0.8 & 2.9 & 284 \\
\hline 15 & 0 & 0 & 0 & 3.3 & 0.8 & 2.3 & 251 \\
\hline
\end{tabular}

To construct the regression equation, the formulas for estimating the coefficients were used in the case of the implementation of the plan of a full factorial experiment, the resulting response surface was analyzed by the method of ridge analysis [26].

To interpret the obtained simulation results from the point of view of microstructural analysis, let's use electron microscopy data from [28].

\section{Results and discussion}

The general structure of the regression equation is:

$$
y=b_{0}+b_{1} x_{1}+b_{2} x_{2}+b_{3} x_{3}+b_{4} x_{1}^{2}+b_{5} x_{2}^{2}+b_{6} x_{3}^{2}+b_{7} x_{1} x_{2}+b_{8} x_{2} x_{3}+b_{9} x_{1} x_{3}+b_{10} x_{1} x_{2} x_{3} .
$$

The following matrix of estimates of the coefficients was obtained in the calculation in a normalized form (Fig. 1): 


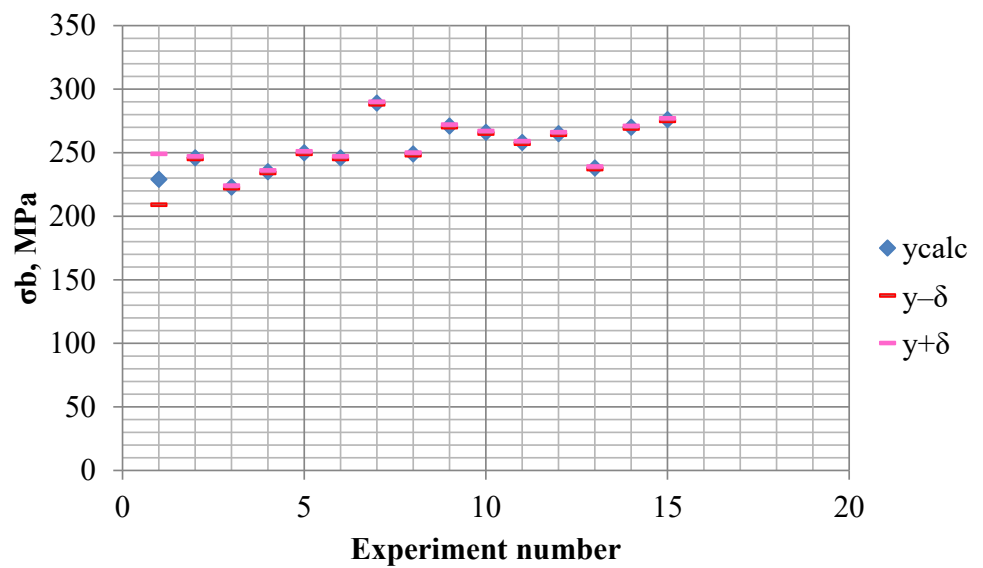

Fig. 1. Calculated and experimental values of the ultimate strength: $y-\delta$ and $y+\delta-$ the lower and upper limits of the confidence intervals, respectively

Since it is of particular interest to elucidate the behavior of the Mn-Al optima at different contents of carbon in the alloy, the value of $\mathrm{x}_{1}$ was fixed at three levels: $-1 ; 0 ; 1$, which corresponded to the following actual carbon content: $\mathrm{C}=3 \%, \mathrm{C}=3.3 \%, \mathrm{C}=3.6 \%$ (Table 1). Substitution of these values into the general equation (2) made it possible to move to the two-dimensional region of the factor space for subsequent ridge analysis. The general structure of the model for ridge analysis in this case is as follows:

$$
y(x, \lambda)=a_{0}+2 a^{\prime} x+x^{\prime} a x+\lambda\left(r^{2}-x^{\prime} x\right),
$$

where $a_{0}$ - initial coefficient, $2 a$ - matrix of estimates of linear coefficients, $A$ - matrix of estimates of nonlinear coefficients, the symbol «'» denotes the operation of transposition of the matrix, $x$ - matrix of input variables, $\lambda$ - Lagrange multiplier, $r$ - radius of the region of restrictions imposed by the experiment planning domain, calculated from the formula:

$$
r^{2}=x^{\prime} x
$$

The matrix of optimal values of the input variables providing the maximum ultimate strength $\left(y_{\max }\right)$ was found by solving equation (5) from the conditions for the existence of a stationary point (6):

$$
\begin{gathered}
x_{o p t}(\lambda)=(\lambda I-A)^{-1} a \\
\frac{1}{2} \frac{\partial y}{\partial x^{\prime}}=a+A x_{o p t}-\lambda x_{o p t}=0 .
\end{gathered}
$$


The solutions to equation (6) are functions $\lambda$ with two poles $\lambda_{1}$ and $\lambda_{2}$, in which the function $r(\lambda) \rightarrow \infty$.

The calculated values of the parameters of equation (3) have the form shown in Tables 2-4 at $x_{1}=-1, x_{1}=0, x_{1}=+1$, respectively.

Table 2

Parameters of equation (3) at $x_{1}=-1$

\begin{tabular}{cccccc}
\hline $\boldsymbol{a}_{\mathbf{0}}$ & $\boldsymbol{a}$ & $\boldsymbol{A}$ & $\boldsymbol{\lambda}_{\mathbf{1}}$ & $\boldsymbol{\lambda}_{\mathbf{2}}$ \\
\hline \multirow{2}{*}{289.2652} & 4.226819 & -9.84273 & 5.5 & & -6.33689 \\
& 10.96218 & 5.5 & -14.9653 & -18.4712 & -
\end{tabular}

Table 3

Parameters of equation (3) at $x_{1}=0$

\begin{tabular}{cccccc}
\hline $\boldsymbol{a}_{\mathbf{0}}$ & $\boldsymbol{a}$ & & $\boldsymbol{A}$ & $\boldsymbol{\lambda}_{\mathbf{1}}$ & $\boldsymbol{\lambda}_{\mathbf{2}}$ \\
\hline \multirow{2}{*}{292.3677} & 1.601819 & -9.84273 & 3.625 & & -16.8426 \\
& 6.46218 & 3.625 & -14.9653 & & -7.96547
\end{tabular}

Table 4

Parameters of equation (3) at $x_{1}=+1$

\begin{tabular}{cccccc}
\hline $\boldsymbol{a}_{\mathbf{0}}$ & $\boldsymbol{a}$ & $\boldsymbol{A}$ & $\boldsymbol{\lambda}_{\mathbf{1}}$ & $\boldsymbol{\lambda}_{\mathbf{2}}$ \\
\hline \multirow{2}{*}{285.3469} & -1.02318 & -9.84273 & 1.75 & & -9.30198
\end{tabular}

The character of the response surfaces for $x_{1}=-1, x_{1}=0, x_{1}=+1$ is shown in Fig. $2-4$ respectively.

The results of the ridge analysis in the form of functions $r(\lambda)$ for the response surfaces shown in Fig. 2-4 are shown in Fig. 5, 8, 11, and in the form of functions $y(r)$ in Fig. 6, 9, 12, respectively. Optimal ratios $x_{2}-x_{3}$ for $x_{1}=-1, x_{1}=0, x_{1}=+1$ are shown in Fig. 7, 10, 13, respectively. The calculation was carried out on the basis of formula (4).

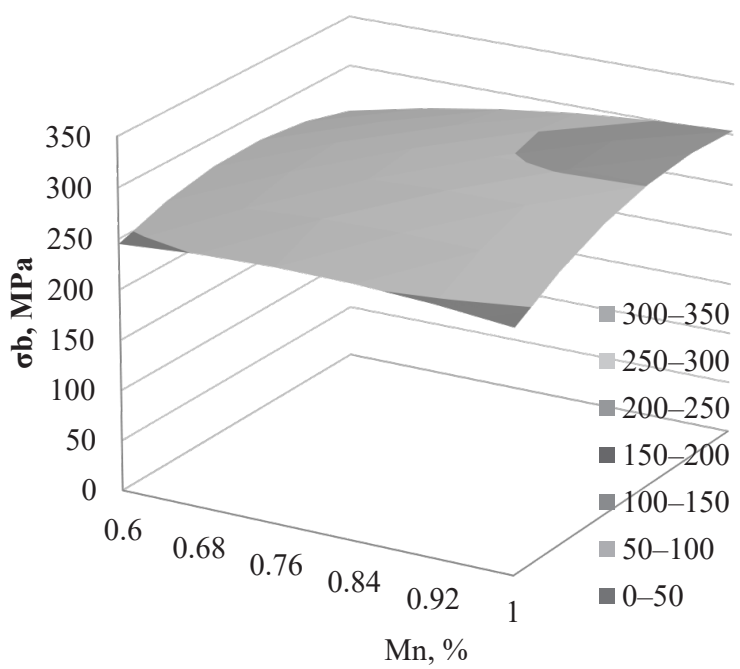

Fig. 2. The nature of the $\mathrm{Mn}-\mathrm{Al}$ response surface for $\mathrm{C}=3 \%$ 


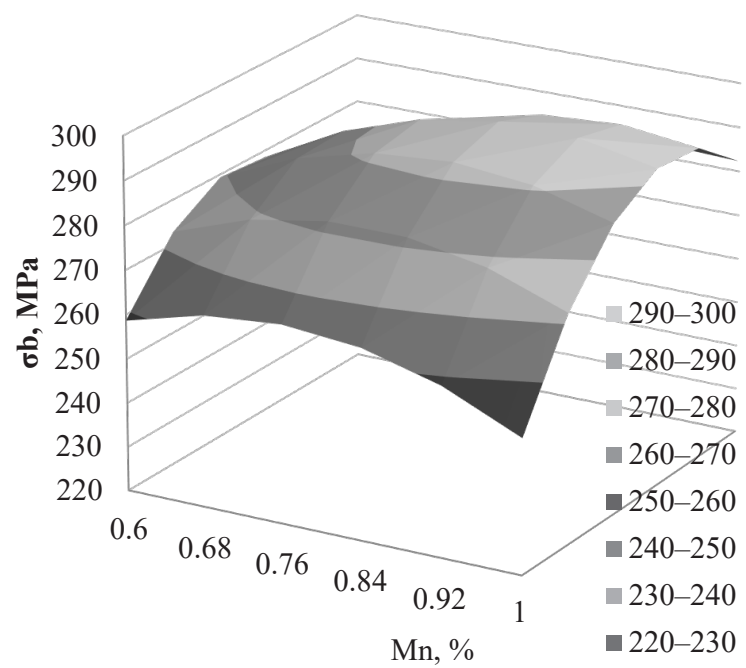

Fig. 3. The nature of the $\mathrm{Mn}-\mathrm{Al}$ response surface for $\mathrm{C}=3.3 \%$

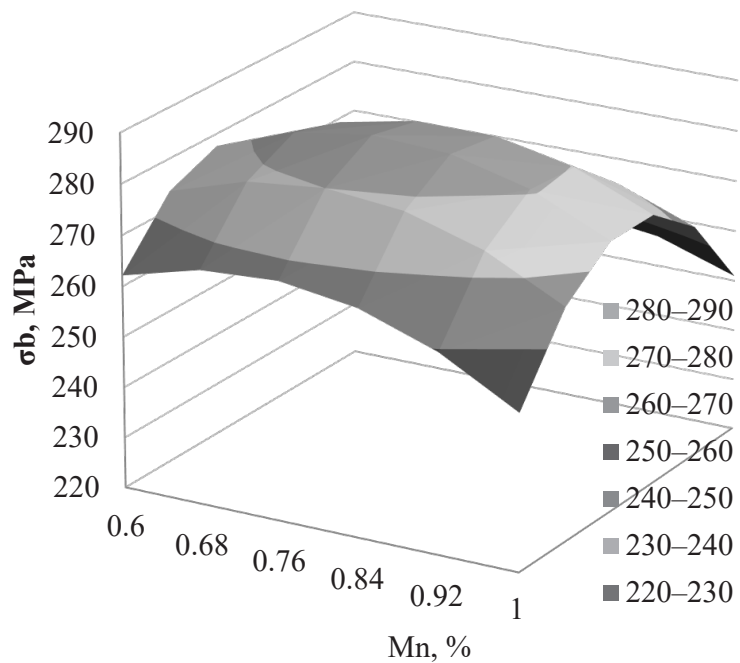

Fig. 4. The nature of the $\mathrm{Mn}-\mathrm{Al}$ response surface for $\mathrm{C}=3.6 \%$

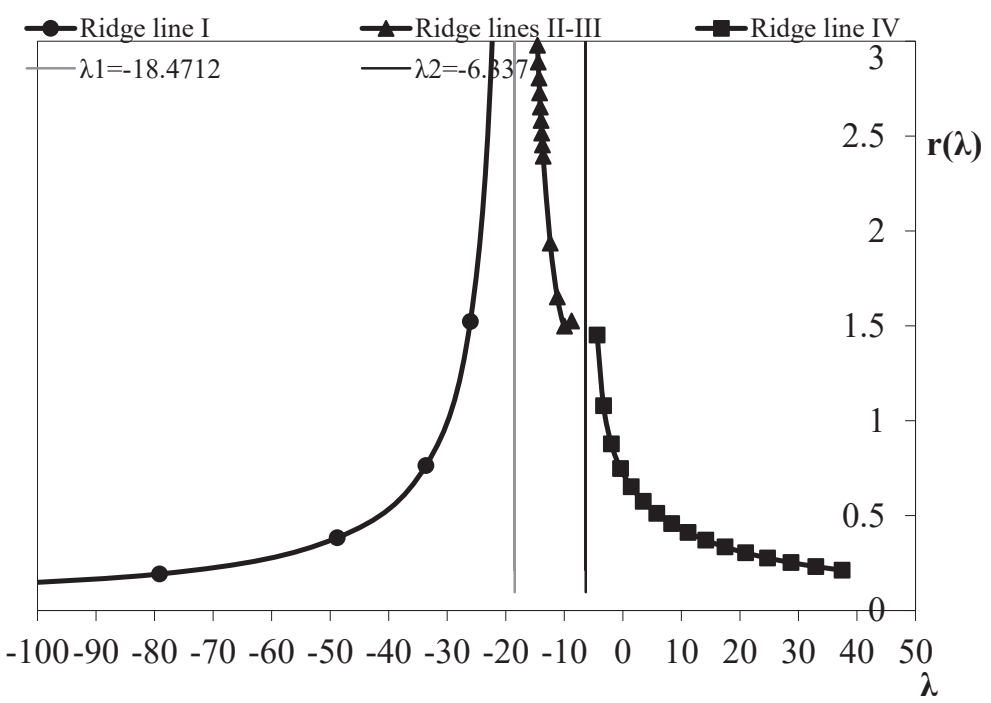

Fig. 5. The results of the ridge analysis in the form of a function $r(\lambda)$ for $x_{1}=-1(\mathrm{C}=3 \%)$ 


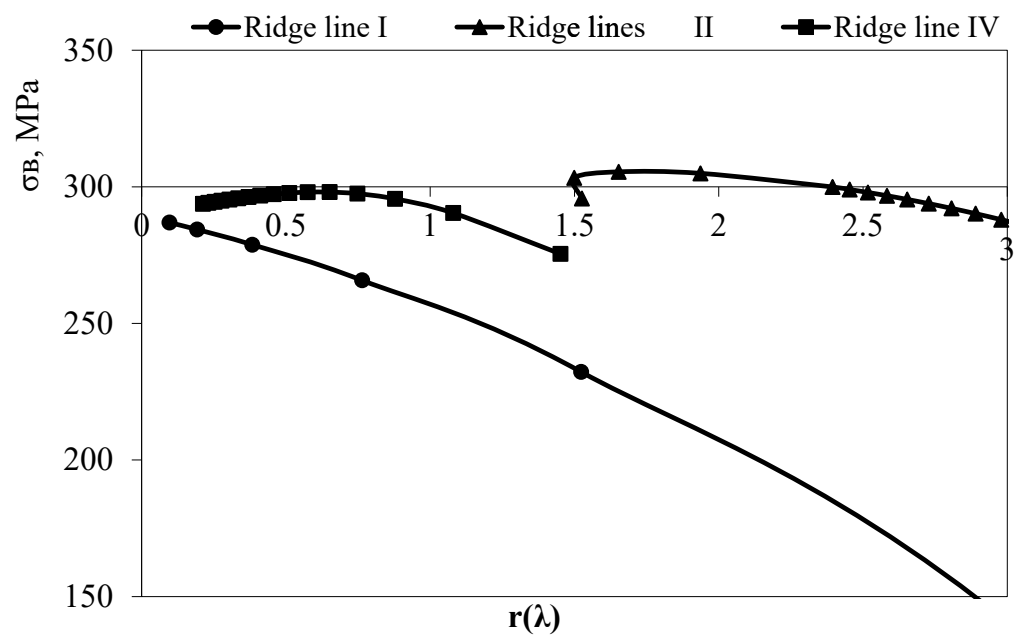

Fig. 6. The results of the ridge analysis in the form of a function $y(r)$ for $x_{1}=-1(\mathrm{C}=3 \%)$

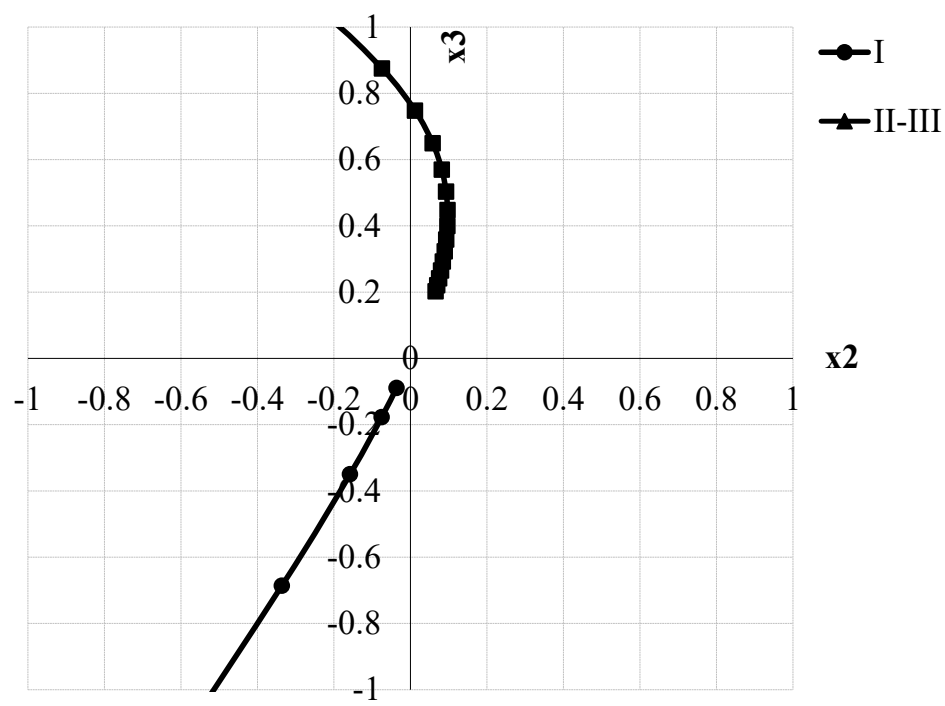

Fig. 7. Optimal ratios $x_{2}-x_{3}$ for $x_{1}=-1(\mathrm{C}=3 \%)$

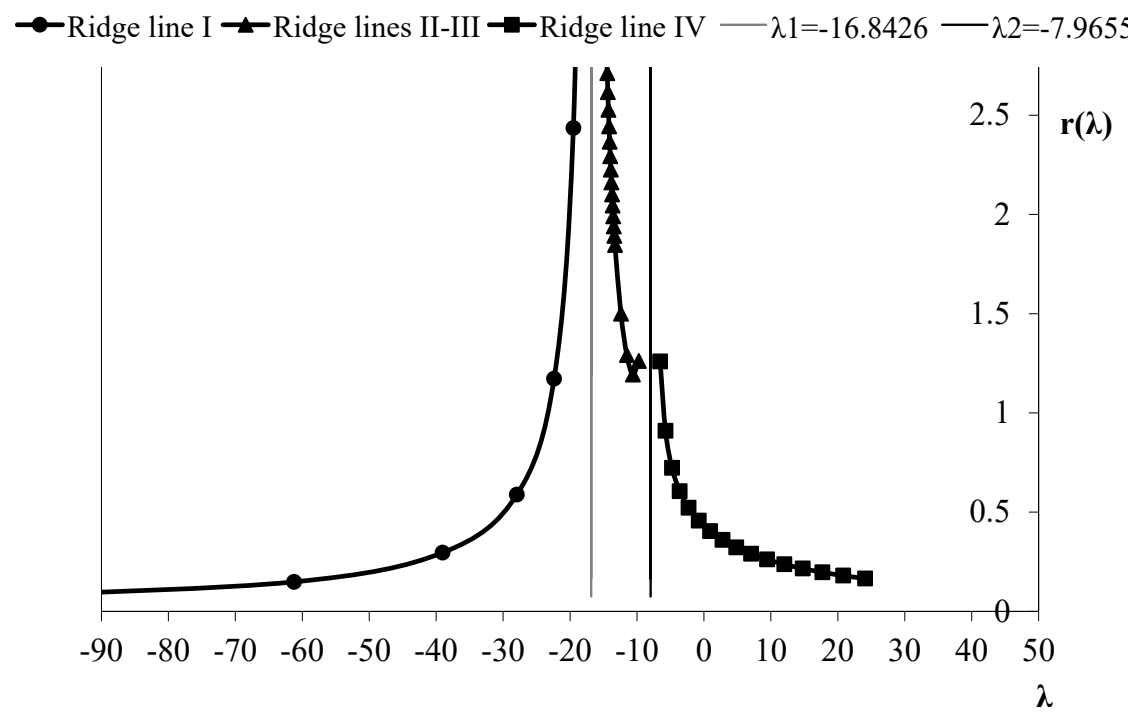

Fig. 8. The results of the ridge analysis in the form of a function $r(\lambda)$ for $x_{1}=-0(\mathrm{C}=3.3 \%)$ 


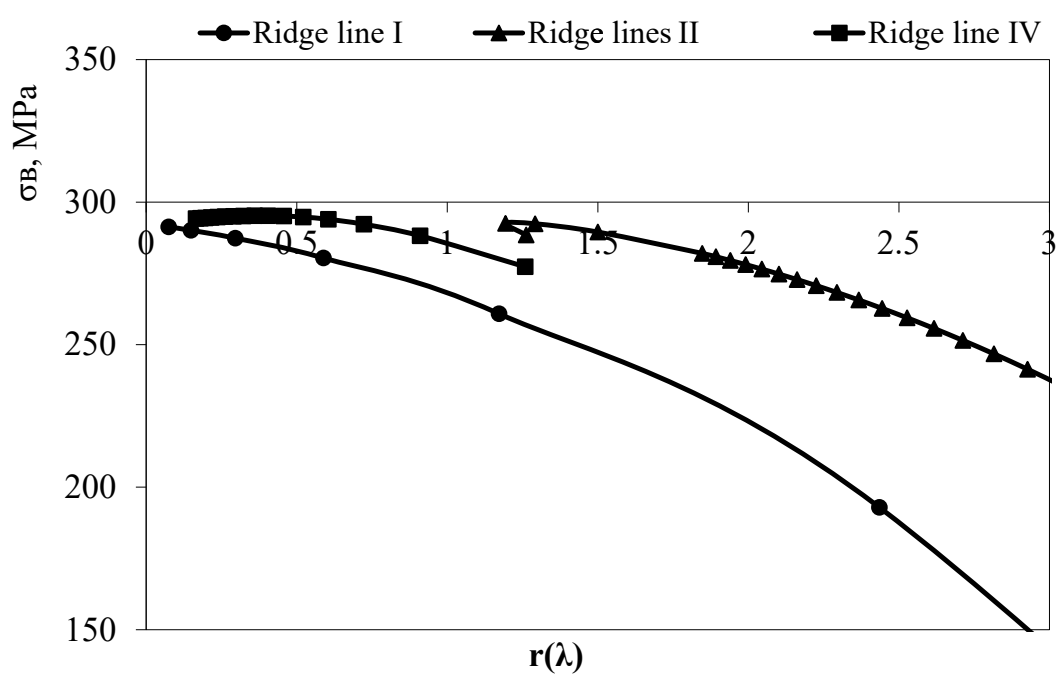

Fig. 9. The results of the ridge analysis in the form of a function $r(\lambda)$ for $x_{1}=-0(\mathrm{C}=3.3 \%)$

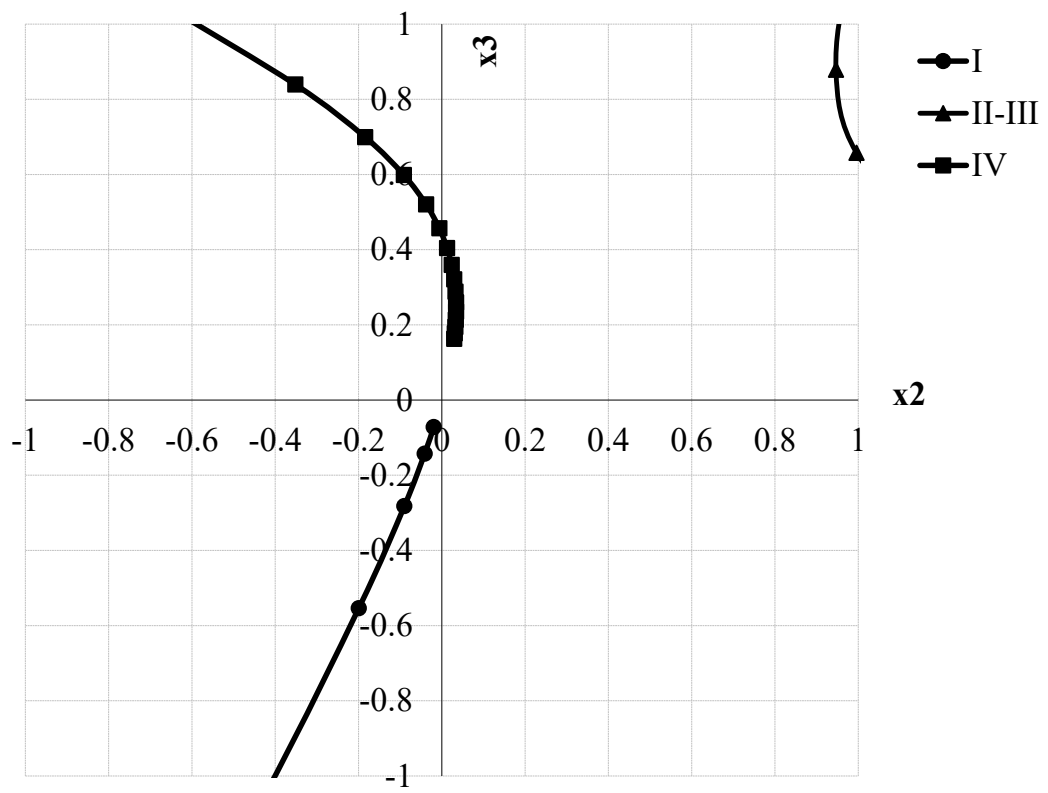

Fig. 10. Optimal ratios $x_{2}-x_{3}$ for $x_{1}=-0(\mathrm{C}=3.3 \%)$

Analysis of Fig. 6,9,12 allows to conclude that the maximum values of the ultimate strength are achieved at the minimum level of carbon content $(\mathrm{C}=3 \%)$ and are in the range of values close to $300 \mathrm{MPa}$. In this case, the $\mathrm{Al}$ content is in the range 0.2-0.6 (in normalized form) - Fig. 7, and the $\mathrm{Mn}$ content remains practically unchanged, approximately 0.1 (in normalized form). In natural units, this is (2.4-2.6) \% $\mathrm{Al} \mathrm{Mn}$. Consequently, to obtain the maximum value of the ultimate strength in the region of $300 \mathrm{MPa}$, it is necessary to keep carbon at a minimum level (3\%), and the $\mathrm{Mn}-\mathrm{Al}$ ratio should be $0.82 \% \mathrm{Mn}-(2.4-2.6) \% \mathrm{Al}$.

If the carbon content increases, then there is a tendency for the optimal content of $\mathrm{Mn}$ and Al to decrease, which is necessary to ensure the ultimate strength close to $300 \mathrm{MPa}$ (Fig. 10). If the carbon content reaches the upper limit of $3.6 \%$, it is impossible to reach the ultimate strength of $300 \mathrm{MPa}$ in the existing range of variation of $\mathrm{Mn}$ and $\mathrm{Al}$. Probably, such results are explained by the fact that Mn has a significant effect on the process of carbide formation, the more developed, under conditions of a minimum carbon content. In such conditions, there is a risk of cementite formation in the structure; therefore, modification should be considered a mandatory technological procedure. However, if the requirements for the castings allow for a lower tensile strength, 
a solution is advisable in which the carbon will be kept at the upper level. This will facilitate the formation of a microstructure during crystallization in a stable manner. It is known that Al has a twofold effect on the process of graphite formation - depending on the range of content, both the process of graphitization and the process of carbide formation can appear. It can be assumed that, in the considered range, $\mathrm{Al}$ influences more as a graphitizing element - the results obtained may indirectly also indicate this. For example, from Fig. 7, 10, 13 it can be seen that in order to ensure the same strength, an increase in the Mn content requires a simultaneous decrease in the Al content. That is, in this case, both elements compensate for the action of each other in terms of the formation of the microstructure. In this case, as evidenced by the results of electron microscopy - Fig. 14 [28], the presence of Al leads to the formation of a more finely dispersed structure of the metal matrix and graphite. This may explain the increase in strength of cast iron containing $\mathrm{Mn}-\mathrm{Al}$ combination in its composition.

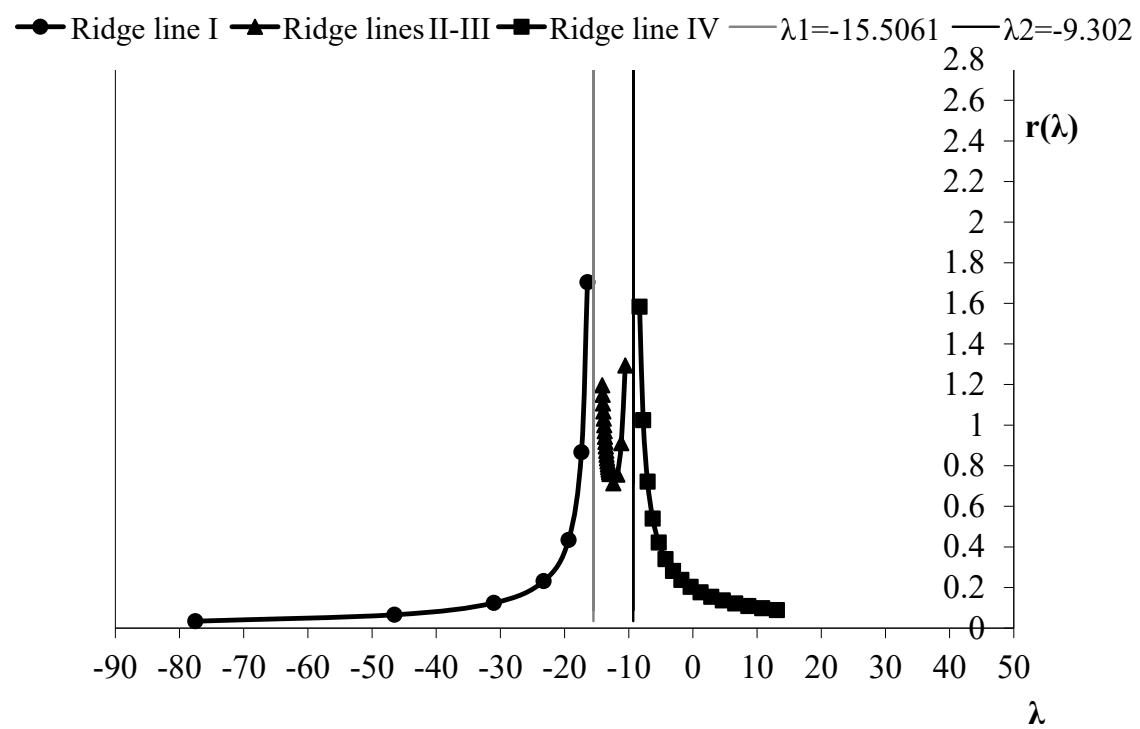

Fig. 11. The results of the ridge analysis in the form of a function $r(\lambda)$ for $x_{1}=+1(\mathrm{C}=3.6 \%)$

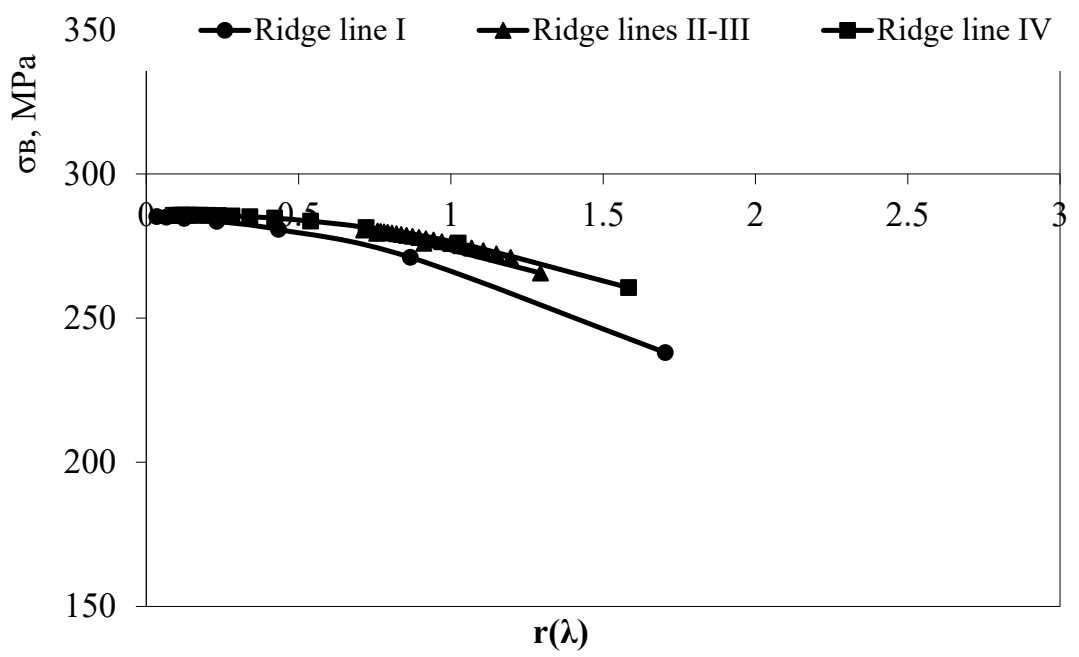

Fig. 12. The results of the ridge analysis in the form of a function $y(r)$ for $x_{1}=+1(\mathrm{C}=3.6 \%)$

The results obtained are limited to the considered range of input variables $\mathrm{C}=(3-3.6) \%$, $\mathrm{Mn}=(0.6-1) \%, \mathrm{Al}=(1.8-2.8) \%$, however, with the possibility of expanding them to the ranges $\mathrm{C}=(2.94-3.66) \%, \mathrm{Mn}=(0.5-1.1) \%, \mathrm{Al}=(1.7-2.9) \%$. 


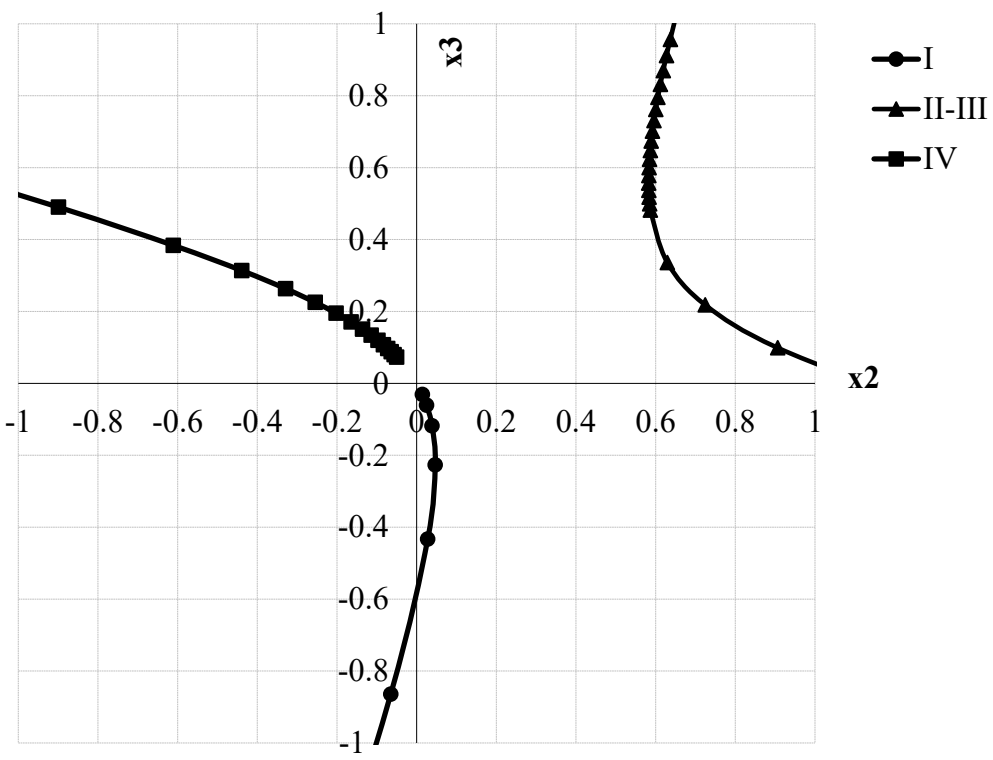

Fig. 13. Optimal ratios $x_{2}-x_{3}$ for $x_{1}=+1(\mathrm{C}=3.6 \%)$

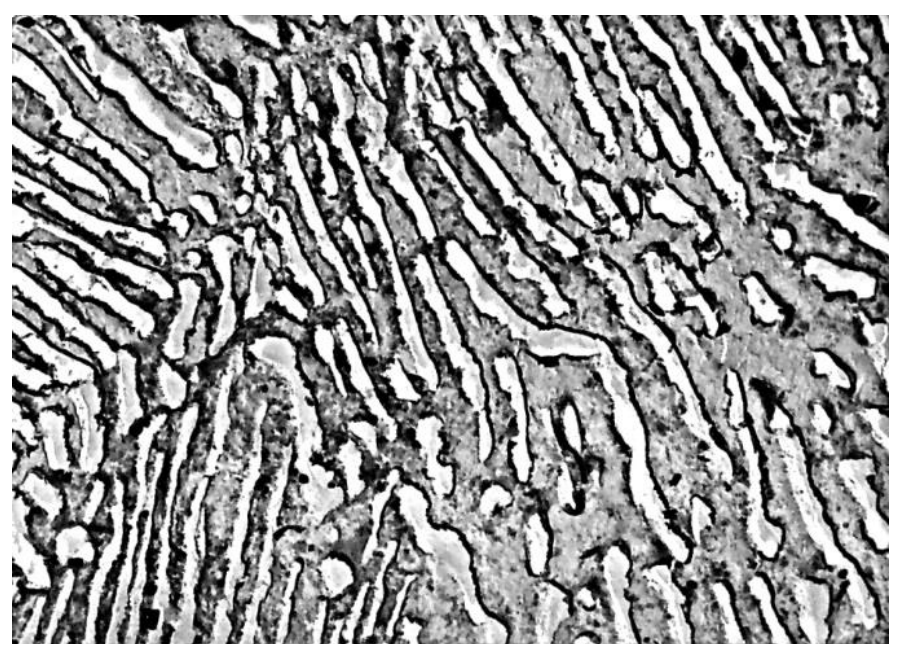

$a$

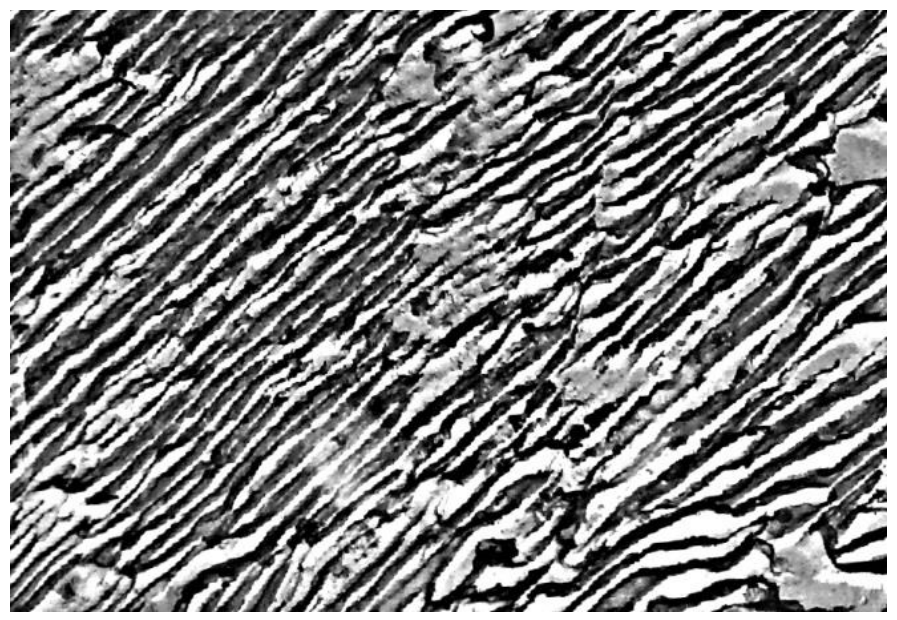

$b$

Fig. 14. Photos of the metal base: $a$ - gray; $b$-aluminum cast irons obtained by electron microscopy [28] 
It is important to note that the results obtained do not contain explicit data on the formation of the microstructure, which would be important in the framework of further research. Moreover, an indirect assessment of the formation of the microstructure can be performed by modeling the influence of the considered elements in the same ranges of variation on the hardness of the alloy.

This is explained by the known fact that the most significant factor influencing strength is the content, size and distribution of carbon in the microstructure, and the most significant factor influencing hardness is the structure of the metal matrix. Since the formation of a microstructure is directly related to whether the crystallization processes proceed according to a stable or metastable scheme, the analysis of the data on the ultimate strength and hardness would allow one to indirectly estimate the scheme according to which scheme the given process proceeds. This may be the subject of further research development.

\section{Conclusions}

The regression equation for the tensile strength of cast iron in the three-factor space of the input variables $\mathrm{C}-\mathrm{Mn}-\mathrm{Al}$ is obtained. On the basis of this equation and the subsequent procedure of the ridge analysis, the optimal combinations of $\mathrm{Mn}-\mathrm{Al}$ are established for three levels of carbon content in the alloy: $\mathrm{C}=3 \%, \mathrm{C}=3.3 \%$ and $\mathrm{C}=3.6 \%$. The solutions obtained are verified for the following ranges of input variables $\mathrm{C}=(2.94-3.66) \%, \mathrm{Mn}=(0.5-1.1) \%, \mathrm{Al}=(1.7-2.9) \%$. It is found that the maximum values of the ultimate strength are achieved at the minimum level of carbon content $(\mathrm{C}=3 \%)$ and are in the range of values close to $300 \mathrm{MPa}$. In this case, the $\mathrm{Al}$ content is in the range $(2.4-2.6) \%$, and the Mn content is about $0.82 \%$. With an increase in the carbon content, there is a tendency to a decrease in the content of $\mathrm{Mn}$ and $\mathrm{Al}$ in the alloy, which is necessary to ensure the ultimate strength close to $300 \mathrm{MPa}$. At the upper limit of the carbon content, it is not possible to reach the ultimate strength of $300 \mathrm{MPa}$ in the existing range of variation of Mn and Al.

The optimal $\mathrm{Mn}-\mathrm{Al}$ ratios obtained in graph-analytical form, depending on the actual content of carbon in the alloy, make it possible to purposefully select the optimal modes for obtaining the alloy, controlling its ultimate strength.

\section{References}

[1] Dymko, I., Muradian, A., Leheza, Y., Manzhula, A., Rudkovskyi, O. (2017). Integrated approach to the development of the effectiveness function of quality control of metal products. Eastern-European Journal of Enterprise Technologies, 6 (3 (90)), 26-34. doi: https://doi.org/10.15587/1729-4061.2017.119500

[2] Akimov, O. V., Koval', O. S., Pulyaev, A. A., Dymko, E. P., Egorenko, T. A., Vysotskiy, S. V. (2015). Quality improvement of cast parts of ice: accounting technological aspects of the automated foundry. Eastern-European Journal of Enterprise Technologies, 6 (1 (78)), 56-62. doi: https://doi.org/10.15587/1729-4061.2015.56039

[3] Dymko, I. (2018). Choice of the optimal control strategy for the duplex-process of induction melting of constructional iron. EUREKA: Physics and Engineering, 4, 3-13. doi: https://doi.org/10.21303/2461-4262.2018.00669

[4] Demin, D. (2020). Constructing the parametric failure function of the temperature control system of induction crucible furnaces. EUREKA: Physics and Engineering, 6, 19-32. doi: https://doi.org/10.21303/2461-4262.2020.001489

[5] Domin, D. (2013). Artificial orthogonalization in searching of optimal control of technological processes under uncertainty conditions. Eastern-European Journal of Enterprise Technologies, 5 (9 (65)), 45-53. doi: https://doi.org/10.15587/ 1729-4061.2013.18452

[6] Dotsenko, Y., Dotsenko, N., Tkachyna, Y., Fedorenko, V., Tsybulskyi, Y. (2018). Operation optimization of holding furnaces in special casting shops. Technology Audit and Production Reserves, 6 (1 (44)), 18-22. doi: https://doi.org/10.15587/ 2312-8372.2018.150585

[7] Cheng, Y., Huang, F., Li, W., Liu, R., Li, G., Wei, J. (2016). Test research on the effects of mechanochemically activated iron tailings on the compressive strength of concrete. Construction and Building Materials, 118, 164-170. doi: https://doi.org/ 10.1016/j.conbuildmat.2016.05.020

[8] Borsato, T., Berto, F., Ferro, P., Carollo, C. (2016). Effect of in-mould inoculant composition on microstructure and fatigue behaviour of heavy section ductile iron castings. Procedia Structural Integrity, 2, 3150-3157. doi: https://doi.org/10.1016/ j.prostr.2016.06.393 
[9] Demin, D. A., Pelikh, V. F., Ponomarenko, O. I. (1998). Complex alloying of grey cast iron. Litejnoe Proizvodstvo, $10,18-19$.

[10] Demin, D. A. (1998). Change in cast iron's chemical composition in inoculation with a Si-V-Mn master alloy. Litejnoe Proizvodstvo, 6,35 .

[11] Bai, Y., Luan, Y., Song, N., Kang, X., Li, D., Li, Y. (2012). Chemical Compositions, Microstructure and Mechanical Properties of Roll Core used Ductile Iron in Centrifugal Casting Composite Rolls. Journal of Materials Science \& Technology, 28 (9), 853-858. doi: https://doi.org/10.1016/s1005-0302(12)60142-x

[12] Endo, M., Yanase, K. (2014). Effects of small defects, matrix structures and loading conditions on the fatigue strength of ductile cast irons. Theoretical and Applied Fracture Mechanics, 69, 34-43. doi: https://oi.org/10.1016/ j.tafmec.2013.12.005

[13] Fourlakidis, V., Diószegi, A. (2014). A generic model to predict the ultimate tensile strength in pearlitic lamellar graphite iron. Materials Science and Engineering: A, 618, 161-167. doi: https://oi.org/10.1016/j.msea.2014.08.061

[14] Chibichik, O., Sil'chenko, K., Zemliachenko, D., Korchaka, I., Makarenko, D. (2017). Investigation of the response surface describing the mathematical model of the effects of the $\mathrm{Al} / \mathrm{Mg}$ rate and temperature on the Al-Mg alloy castability. ScienceRise, 5 (2), 42-45. doi: https://doi.org/10.15587/2313-8416.2017.101923

[15] Makarenko, D. (2017). Investigation of the response surfaces describing the mathematical model of the influence of temperature and $\mathrm{BeO}$ content in the composite materials on the yield and ultimate strength. Technology Audit and Production Reserves, 3 (3 (35)), 13-17. doi: https://doi.org/10.15587/2312-8372.2017.104895

[16] Demin, D. A., Pelikh, V. F., Ponomarenko, O. I. (1995). Optimization of the method of adjustment of chemical composition of flake graphite iron. Litejnoe Proizvodstvo, 7-8, 42-43.

[17] Domina, O. (2020). Selection of alternative solutions in the optimization problem of network diagrams of project implementation. Technology Audit and Production Reserves, 4 (4 (54)), 9-22. doi: https://doi.org/10.15587/ 2706-5448.2020.210848

[18] Akimov, O., Penzev, P., Marynenko, D., Saltykov, L. (2018). Identification of the behavior of properties of a cold-hardening glass-liquid mixture with propylene-carbonate different in dosing components. Technology Audit and Production Reserves, 2 (3 (46)), 4-9. doi: https://doi.org/10.15587/2312-8372.2019.169748

[19] Demin, D. (2017). Synthesis of nomogram for the calculation of suboptimal chemical composition of the structural cast iron on the basis of the parametric description of the ultimate strength response surface. ScienceRise, 8 (37), 36-45. doi: https://doi.org/10.15587/2313-8416.2017.109175

[20] Demin, D. (2017). Strength analysis of lamellar graphite cast iron in the «carbon (C) - carbon equivalent $\left(\mathrm{C}_{e q}\right)$ » factor space in the range of $\mathrm{C}=(3.425-3.563) \%$ and $\mathrm{C}_{e q}=(4.214-4.372) \%$. Technology Audit and Production Reserves, 1 (1 (33)), $24-32$. doi: https://doi.org/10.15587/2312-8372.2017.93178

[21] Zinchenko, P. S., Aksenenko, M. P., Yovbak, A. V., Orendarchuk, Yu. V. (2016). Application of liquid glass mixtures with reduced content of liquide glass as a factor in improving the quality of machine-building castings. ScienceRise, 5 (2 (22)), 6-9. doi: https://doi.org/10.15587/2313-8416.2016.69836

[22] Domina, O., Lunin, D., Barabash, O., Balynska, O., Paida, Y., Mikhailova, L., Niskhodovska, O. (2018). Algorithm for selecting the winning strategies in the processes of managing the state of the system «supplier - consumer» in the presence of aggressive competitor. Eastern-European Journal of Enterprise Technologies, 6 (3 (96)), 48-61. doi: https://doi.org/10.15587/ 1729-4061.2018.152793

[23] Domina, O. (2020). Features of finding optimal solutions in network planning. EUREKA: Physics and Engineering, 6, 82-96. doi: https://doi.org/10.21303/2461-4262.2020.001471

[24] Demin, D. (2018). Investigation of structural cast iron hardness for castings of automobile industry on the basis of construction and analysis of regression equation in the factor space «carbon $(\mathrm{C})$ - carbon equivalent $\left(\mathrm{C}_{e q}\right)$ ». Technology Audit and Production Reserves, 3 (1 (41)), 29-36. doi: https://doi.org/10.15587/2312-8372.2018.109097

[25] Mohanad, M. K., Kostyk, V., Domin, D., Kostyk, K. (2016). Modeling of the case depth and surface hardness of steel during ion nitriding. Eastern-European Journal of Enterprise Technologies, 2 (5 (80)), 45-49. doi: https://doi.org/10.15587/ 1729-4061.2016.65454

[26] Demin, D. (2017). Synthesis of optimal control of technological processes based on a multialternative parametric description of the final state. Eastern-European Journal of Enterprise Technologies, 3 (4 (87)), 51-63. doi: https://doi.org/10.15587/ 1729-4061.2017.105294

[27] Frolova, L., Shevchenko, R., Shpyh, A., Khoroshailo, V Antonenko, Y. (2021). Selection of optimal Al-Si combinations in cast iron for castings for engineering purposes. EUREKA: Physics and Engineering, 2, 99-107. doi: https://doi.org/10.21303/ 2461-4262.2021.001694 
[28] Zatolokin, E. A., Skiba, V. P., Mis'kevich, V. I., Saltykova, I. A., Mityagin, L. Ya. (1976). Issledovanie svoystv i razrabotka tekhnologii proizvodstva otlivok iz vysokokachestvennogo alyuminievogo chuguna. Otchet o NIR, tema No. 19142, 104.

[29] Demin, D. (2019). Development of «whole» evaluation algorithm of the control quality of «cupola - mixer» melting duplex process. Technology Audit and Production Reserves, 3 (1 (47)), 4-24. doi: https://doi.org/10.15587/ 2312-8372.2019.174449

How to cite: Popov S., Frolova L.,Rebrov O., Naumenko Ye., Postupna O., Zubko V., Shvets P. (2022). Increasing the mechanical properties of structural cast iron for machine-building parts by combined Mn-Al alloying. EUREKA: Physics and Engineering, 1, 118-130. doi: https://doi.org/10.21303/2461-4262.2022.002243 